\title{
Effects of Haruan (Channa striatus) Based Cream on Acute Inflammation in Croton Oil Induced Mice Ear Edema Model
}

\author{
Sadegh Abedi, Fatemeh Ehtesham Far, Mohd. Khairi Hussain, \\ Zuraini Ahmad and Abdul Manan Mat Jais \\ Department of Biomedical Sciences, Faculty of Medicine and Health Sciences, \\ Universiti Putra Malaysia, 43400 UPM Serdang, Selangor, Malaysia
}

\begin{abstract}
Inflammation is a non-specific reaction of body tissues against harmful stimulus, injury or infection to protect the body and promote the recovery process. Myeloperoxidase a pro-inflammatory enzyme released by activated neutrophils and macrophages is frequently used as a marker of polymorphonuclears accumulation in different tissue samples. Haruan (Channa striatus) is a tropical, snakehead, freshwater, air breathing and carnivorous fish belongs to family channadae which is indigenous to Malaysia. The current study was undertaken to identify the properties of a new haruan based cream as a natural product on myeloperoxidase enzyme as a marker of polymorphonuclears accumulation. In the present study, anti-inflammatory activity of haruan (Channa striatus) based cream (at doses 1, 5 and 10\%) on the ear thickness and myeloperoxidase activity (as two acute inflammation indexes) were studied using croton oil induced ear edema method and compared with effects of hydrocortisone $1 \%$ cream as reference drug. Results showed that all percentages of haruan based cream in a same potent with reference treatment significantly inhibited edema at 4 and $24 \mathrm{~h}$ after croton oil application $(\mathrm{p}<0.05)$. Besides, myeloperoxidase assay results shown that topical application of these three different dosages of haruan based cream also block migration of polymorphonuclear leukocytes to the dermis as effective as hydrocortisone cream $1 \%$ and in a dose dependent manner $(\mathrm{p}<0.05)$. Evidences obtained from the present study, on the one side, support the previous results that had shown the anti-inflammatory effects of haruan extracts in other animal models and on the other side, introduce a new topical biomedical product with a potency as great as hydrocortisone in inhibition of inflammation. It is suggested that topical anti-inflammatory effects of haruan based cream is contributed to its bioactive substances content such as linoleic acid, stearic acid, oleic acid and $\mathrm{N}$-arachidonylplycine.
\end{abstract}

Key words: Haruan (Channa striatus), Haruan based cream, acute inflammation, croton oil, Myeloperoxidase (MPO)

\section{INTRODUCTION}

Inflammation is a non-specific reaction of body tissues against harmful stimulus, injury or infection to protect the body and promote the recovery process (Krishnaraju et al., 2009). There are two basic types of inflammation acute and chronic. Increased blood flow and capillary permeability, macrophage phagocytosis, restraining of bacteria and strange matters and accumulation of Polymorphonuclear leukocytes (PMNs) are four major events during early stage of acute inflammation (William and Stanfield, 2002).

A large group of disorders such as cancer, asthma, celiac, inflammatory bowel diseases, rheumatoid arthritis, allergies and sarcoidosis are originated from an inflammatory condition.
Myeloperoxidase (MPO); a pro-inflammatory enzyme released by activated neutrophils and macrophages is frequently used as a marker of PMNs accumulation in different tissue samples. MPO is a hemoprotein which its main storages are azurophilic granules of polymorphonuclear neutrophils and macrophages. MPO on the one hand, catalyzes the production of Hypochlorite $(\mathrm{HOCl})$ from one chloride ion $\left(\mathrm{Cl}^{-}\right)$and Hydrogen peroxide $\left(\mathrm{H}_{2} \mathrm{O}_{2}\right)$ and on the other hand decreases the vasodilating and anti-inflammatory effects of endothelial derived Nitric Oxide (NO) via lessening its bioavailability (Faith et al., 2008). The common methods for measuring MPO concentrates in plasma and tissue samples including histochemical staining, immunecytochemistry and flow cytometry (Matsuo et al., 2003).

Corresponding Author: Sadegh Abedi, Department of Biomedical Sciences, Faculty of Medicine and Health Sciences, Universiti Putra Malaysia, 43400 UPM Serdang, Selangor, Malaysia 
Haruan (Channa striatus) is a tropical, snakehead, freshwater air breathing and carnivorous fish belongs to family Channadae which is indigenous to Malaysia. Local peoples are believed that haruan reduces pain and use it mostly for treating mothers after delivery and any post-operative pain (Mat Jais et al., 1998). Wound healing (Mat Jais et al., 1994; Baie and Sheikh, 2000), anti-eczem a (Mat Jais et al., 1997), antiniciceptive (Mat Jais et al., 1998) and platelet aggregation (Mat Jais, 2007) are some well known pharmacological properties of haruan are demonstrated till now. The high contents of Arachidonic Acid (AA) (Mat Jais et al., 1994) and essential amino acids (specially glycine) have been shown that are responsible for blood clothing, wound healing and antinociceptive activities of haruan (Zakaria et al., 2006). Besides, there are four preliminary studies have reported that haruan extract has potent anti-inflammatory property (Somchit et al., 2004; Mohd. Hassan, 2005). But to the knowledge, no research was done to study the effect of haruan aqueous extract on PMNs accumulation. So, the current study was undertaken to identify the properties of a new haruan based cream as a natural product on MPO enzyme as a marker of PMN's accumulation.

\section{MATERIALS AND METHODS}

Preparation of Haruan (Channa striatus) extract: The aqueous extract was prepared using Channa striatus fresh fillet based on a method demonstrated by Mat Jais et al. (1994). After washing with distilled water, each medium alive fish (weighting between $200-400 \mathrm{~g}$ ) was placed into a plastic bag contained distilled water (at ratio $1: 1$ to the weight of fish) and was kept in freezer at $0^{\circ} \mathrm{C}$ for $12 \mathrm{~h}$. After thawing, the boneless fillets were prepared and in mix with distilled water at ratio 1:4 (fish weight:water volume) were placed into a stainless steel pressure cooker set at $100^{\circ} \mathrm{C}$ for $2 \mathrm{~h}$. The mentioned ratio was kept during cooking period by adding sufficient distilled water every $30 \mathrm{~min}$. In the next step, the steamed fish fillets were discarded and liquid extract was collected, filtered using filter paper (Whatman ${ }^{\circledR}$ No. 1 UK), centrifuged using ultra-centrifuge (Beckman Coulterxl-100k) 10,000 $\times \mathrm{g}$ for $5 \mathrm{~min}$ and stored at $4^{\circ} \mathrm{C}$.

Preparation of Haruan extract based cream: For preparation of $100 \mathrm{~mL}$ Haruan extract cream in percentages of 1,5 and $10 ; 1,5$ and $10 \mathrm{~mL}$ of Haruan extract was added to 99,95 and $90 \mathrm{~mL}$ of aqua cream (UPHA Pharmaceutical Manufacturing, Malaysia), respectively. This aqua cream was used as basis and contained emulsifying wax $8 \%$ $\mathrm{w} / \mathrm{w}$, white soft paraffin $12 \% \mathrm{w} / \mathrm{w}$, liquid paraffin $8 \% \mathrm{w} / \mathrm{w}$, methylparaben $0.32 \% \mathrm{w} / \mathrm{w}$ and propylparaben $0.048 \%$ $\mathrm{w} / \mathrm{w}$. All preparations were homogenized using homogenizer (Wiggen Hauser ${ }^{\circledR}$ D-500, Germany) at $3000 \mathrm{rpm}$ for $5 \mathrm{~min}$ and stored at $4^{\circ} \mathrm{C}$ until use.

Experimental animals: About 42 adult male ICR mices (weighting between 23-28 g) were utilized in the current study. All animal experiments were approved by Animal Care and Use Committee (ACUC) Ref., UPM/FPSK/ $\mathrm{PADS} / \mathrm{UUH} / \mathrm{FO}$, Faculty of Medicine and Health Sciences of University Putra Malaysia. Mice were housed in group of 7 in plastic cages with free access to standard rodent food and water in a well air conditioned animal room at $30 \pm 3^{\circ} \mathrm{C}$ and $12 \mathrm{~h}$ light $12 \mathrm{~h}$ dark cycle. Animals were acclimated under the mentioned condition 1 week prior to the experiments. The sample size of 7 mice for each experimental group was justified.

Croton oil induced mice ear edema: All 42 mice were randomly divided to 6 equal groups including three comparisons and three treatments. Comparison groups were included to negative control which received only basic cream, vehicle group which received both croton oil and basic cream and finally positive control group which received both croton oil and hydrocortisone 1\% cream (Xepa-Soul Pattinson, Malaysia). Animals in treatment group 1-3 were treated with Haruan based cream 1, 5 and $10 \%$, respectively. To avoid effects of endogenous steroids circadian rhythm on the inflammatory reactions, inflammation was induced in period of 10-11:30 a.m. (Soliman et al., 1983). After anesthetizing of all animals with $145 \mathrm{mg} \mathrm{kg}^{-1}$ intraperitoneal ketamine hydrochloride (Bioketan $($ Vetoquinol BIOWET, Poland), inflammation was induced using $10 \mu \mathrm{L}$ croton oil (Sigma-Aldrich ${ }^{\circledR}$, C6719-10G China) in all mice except negative control group (Cabrini et al., 2010). About $30 \mathrm{~min}$ following to induce inflammation animals in treatment group 1-3 were treated with Haruan based cream 1, 5 and $10 \%$, respectively.

At the same time animals in negative control, reference and vehicle groups were treated with basic cream, hydrocortisone $1 \%$ cream and basic cream again, respectively (Fariba et al., 2009). All creams were applied in amount of $0.3 \mathrm{~g}$ in both inner and outer surfaces of both ears and with gentle rubbing 50 times with the index finger covered with latex glove. A digital micrometer (Mitutoyo Series IP65, Coolant Proof, Japan) was applied to measure ear thickness as the first indicator of ear edema at 4 and $24 \mathrm{~h}$ after croton oil application. Measurements were done near the top of the ear distal to cartilaginous ridges. Percent inhibition of inflammation for each group and at each measurement time was calculated using equation as (Okoli et al., 2007): 
Res. J. Biol. Sci., 7 (4): 181-187, 2012

Percentinhibition

of inflammation $=\left[1-\left(\frac{a-x}{\beta-y}\right)\right] \times 100$

Where:

$\alpha=$ Mean ear thickness of treatments and control 3 groups mice at various time after croton oil application

$\mathrm{x}=$ Mean ear thickness of treated mice before croton oil application

$\beta=$ Mean ear thickness of control group 2 mice at various time after croton oil application

$\mathrm{y}=$ Mean ear thickness of control group 2 mice before croton oil application

Ear punch biopsies: About $24 \mathrm{~h}$ after inducing edema all animals were sacrificed with chloroform inhalation according to the ACUC approved protocol at the Faculty of Medicine and Health Sciences of University Putra Malaysia. About $6 \mathrm{~mm}$ ear punch biopsies were taken immediately using biopsy punch (Easy Punch $6.0 \mathrm{~mm}$, Cardiograph Corporation, India), weighted and rinsed with iced-cold PBS (0.02 M, pH 7.2) (Sigma-Aldrich ${ }^{\circledR}$, P5368) to remove excess blood.

Myeloperoxidase (MPO) assay: Tissue MPO activity was measured using ELISA kit for mice MPO (Uscn Life Science Inc., Wuhan, E0601 Mu, China). All ear biopsies were minced using surgical blade, homogenized with tissue homogenizer (Biospec Products, Model 985-370, USA) and finally stored at $-20^{\circ} \mathrm{C}$ for $18 \mathrm{~h}$. Following to two freeze-thaw cycles in aiming to break cell membrane, the homogenized samples were centrifuged for $15 \mathrm{~min}$ at $8000 \times \mathrm{g}$ and $4^{\circ} \mathrm{C}$ using centrifuge (Hettich, Model 320R, USA). After removing the supernatant, it was divided to three equal portions and stored at $-20^{\circ} \mathrm{C}$ till use. Seven standard reagents (with concentrations 25, 12.5, 6.25, 3.12, $1.56,0.78$ and 0.39 ) one blank reagent, assay diluents $\mathrm{A}$ and $\mathrm{B}$ detection reagents $\mathrm{A}$ and $\mathrm{B}$ and wash solution were prepared based on instruction manual of USCN Company. After thawing, $100 \mu \mathrm{L}$ from homogenate samples, standard reagents and blank were added to 96-well plate in an appropriate order shown in Fig. 1 and were incubated for $2 \mathrm{~h}$ at $37^{\circ} \mathrm{C}$. In the following step, all wells were replaced with $100 \mu \mathrm{L}$ of detection reagent $\mathrm{A}$ and incubating was repeated for $1 \mathrm{~h}$ at $37^{\circ} \mathrm{C}$. After 3 times washing with $350 \mu \mathrm{L}$ washing solution, $100 \mu \mathrm{L}$ of detection reagent $\mathrm{B}$ was added to wells and the plate was incubated for more $30 \mathrm{~min}$ at $37^{\circ} \mathrm{C}$. After the mentioned period washing process was repeated for 5 times and $90 \mu \mathrm{L}$ of $\mathrm{TMB}$ substrate $\left(3,3^{\prime}, 5,5^{\prime}\right.$-tetramethylbenzidine) was cast in each well and incubating was done for $20 \mathrm{~min}$ at $37^{\circ} \mathrm{C}$. The reaction was stopped with the addition of $50 \mu \mathrm{L}$ of stop

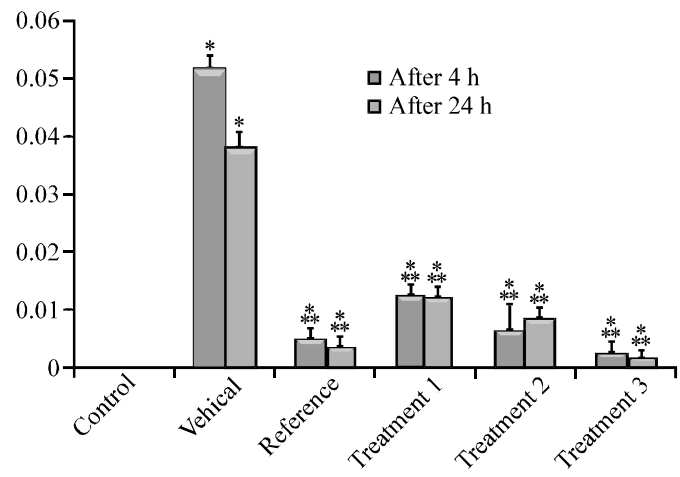

Fig. 1: Change in ear thickness 4 and $24 \mathrm{~h}$ after croton oil application. Results represent means \pm SEM. ${ }^{*} \mathrm{p}<0.05$ compared to control (no croton oil) and $* * \mathrm{p}<0.05$ compared to vehicle group

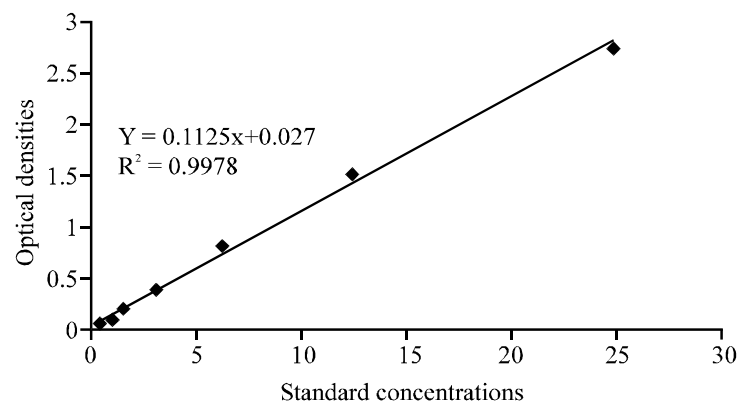

Fig. 2: Standard curve for mouse Myeloperoxidase (MPO) ELISA

solution (sulfuric acid $\mathrm{pH}$ 3.0) to each well. MPO enzyme was measured colorimetrically using microplate reader (Tecan Infinite ${ }^{\mathrm{TM}}$, Series $200, \mathrm{USA}$ ) at $450 \mathrm{~nm}$ absorbance wavelength. MPO activity was expressed as Optical Density (OD) per biopsy. Since the number of samples was 84 so the triplicate readings of standards, blank and samples during a single session was not possible. Therefore, three different assay sessions with same standards, blank and samples were conducted.

Result calculation and statistic analysis: For MPO assay, averages of the triplicate readings for each standard and sample were deducted the averages of blank (zero standard) OD. A standard curve was drawn applying Microsoft Office Excel 2007 and the MPO concentrations were calculated based on the equation of this standard curve. Values of MPO concentrations for each sample from reference and treatment groups were calculated based on equation of standard curve $y=0.1125 x+0.027$ (Fig. 2). All values are expressed as the mean \pm Standard Error of the Mean (SEM). Results were analyzed using 
t-test and one-way Analysis of Variance (ANOVA) followed by Tukey as post-hoc test option in SPSS 18.0 Software. Significant differences were accepted at $(\mathrm{p}<0.05)$.

\section{RESULTS AND DISCUSSION}

Ear thickness: Significant difference between ear edema mean changes in negative control and vehicle groups has proved the effectiveness of croton oil in inducing edema $(\mathrm{p}<0.05)$ (Fig. 1). Ear edema was measured in all croton oil treated animals (vehicle, reference and treatment group 1-3) before 4 and $24 \mathrm{~h}$ after treatment. In vehicle group, initial ear thickness of animals was $0.23 \pm 0.0025 \mathrm{~mm}$ (mean \pm SEM). At 4 and $24 \mathrm{~h}$ after croton oil application, ear thickness increased to $0.28 \pm 0.0023$ and $0.27 \pm 0.0017 \mathrm{~mm}$ (mean \pm SEM), respectively (Table 1). At the same intervals, animals in reference and treatment groups showed significantly reduced in ear edema compared to vehicle group $(\mathrm{p}<0.05$ ) (Fig. 1). By both 4 and $24 \mathrm{~h}$ after croton oil application, Haruan based cream at 1, 5 and $10 \%$ dosages was effective as hydrocortisone cream $1 \%$ in reducing edema $(\mathrm{p}<0.05)$. At $4 \mathrm{~h}$ compared to vehicle group, three mentioned treatments inhibited edema by 76 , 89 and $95 \%$, respectively versus reference drug which inhibited edema by $92 \%$. At $24 \mathrm{~h}$ three dosages of Haruan based cream reduced ear edema by 68,78 and $98 \%$, respectively whereas hydrocortisone done by $92 \%$. Even though, the obtained data showed that Haruan based cream $10 \%$ at $24 \mathrm{~h}$ was significantly more effective than $5 \%$ in inhibiting of ear edema $(\mathrm{p}<0.05)$.

MPO assay: Mean MPO concentration of biopsies taken from ears treated with hydrocortisone cream $1 \%$ and Haruan based cream at 1,5 and $10 \%$ were $3.20 \pm 0.080$, $3.74 \pm 0.110, \quad 3.44 \pm 0.060$ and $2.72 \pm 0.025 \mathrm{ng} \mathrm{mL} \mathrm{mL}^{-1}$ (mean \pm SEM), respectively (Table 2 ). In comparison with

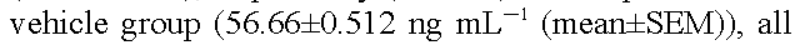
three dosages of Haruan based cream and reference drug had significantly reduced MPO concentration $(\mathrm{p}<0.05)$ (Fig. 3). Hydrocortisone cream 1\% decreased MPO to $5.6 \%$ of the concentration of vehicle group. Results showed that haruan based cream in dosages 1,5 and $10 \%$ without any significant difference in comparison together, reduced MPO to $3.7,3.4$ and $2.7 \%$ of the concentration of vehicle group, respectively. Even thought, the mentioned experimental cream at $10 \%$ was more effective than it at $5 \%(\mathrm{p}<0.05)$.

In the present study, topical properties of a new natural product Haruan (Channa striatus) based cream on the mouse ear edema and MPO activity as two indexes of acute inflammation were evaluated. In summary, all percentages of Haruan based cream in a same potent with reference treatment hydrocortisone cream $1 \%$, significantly inhibited edema at 4 and $24 \mathrm{~h}$ after croton oil application. Besides, MPO assay results shown that topical application of these three different dosages of haruan based cream also block migration of $\mathrm{PMN}$ leukocytes to the dermis as effective as hydrocortisone cream $1 \%$ and in a dose dependent manner. Vasodilation, exudation of plasma and migration of primarily neutrophils into the injury or infected site are three major events during acute inflammation (Sherwood and Toliver-Kinsky, 2004). Croton oil which used in this study to induce inflammation is contains 12-0-Tetradecanoylphorbol-13Acetate (TPA). TPA inducing edema via increasing the formation of eicosanoids such as Prostaglandin $\mathrm{E}_{2}\left(\mathrm{PGE}_{2}\right)$ and Leukotriene $\mathrm{B}_{4}\left(\mathrm{LTB}_{4}\right)$ inducing production of pro-inflammatory cytokines such as TNF- $\alpha$ in keratinocytes and increasing mast cell infiltration (Bralley et al., 2008). In the current study, croton oil induced mice ear edema was preferred to other animal inflammation models because it is characterized by elevated ear weight, epidermal hyperplasia and neutrophil infiltration (Nakadate, 1989).

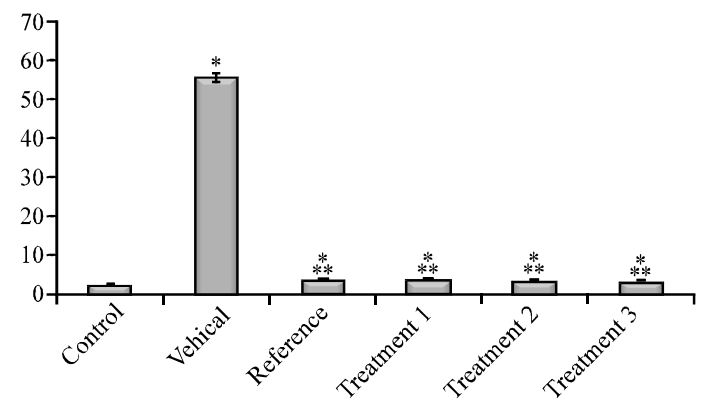

Fig. 3: Myeloperoxidase concentrations results represent means \pm SEM. ${ }^{*} \mathrm{p}<0.05$ compared to control (no croton oil) and $* * \mathrm{p}<0.05$ compared to vehicle group

Table 1: Changes of ear thickness after 4 and $24 \mathrm{~h}$

\begin{tabular}{lccc}
\hline & After $4 \mathrm{~h}$ & After 24h \\
Groups & $\begin{array}{c}\text { Ear thickness changes } \\
(\mathrm{mm})(\mathrm{n}=7)\end{array}$ & $\begin{array}{c}\text { Inhibition of } \\
\text { inflammation }(\%)\end{array}$ & $\begin{array}{c}\text { Ear thickness } \\
\text { changes (mm) }(\mathrm{n}=7)\end{array}$ \\
\hline Vehicle & $0.051778 \pm 0.0023$ & - & $\begin{array}{c}\text { Inhibition of } \\
\text { inflammation }(\%)\end{array}$ \\
Reference & $0.004157 \pm 0.0032$ & 92 & $0.037286 \pm 0.0036$ \\
Treatment 1 (dose 1\%) & $0.0124 \pm 0.0020$ & 76 & $0.011929 \pm 0.0017$ \\
Treatment 2 (dose 5\%) & $0.005571 \pm 0.0055$ & 89 & $0.008286 \pm 0.0023$ \\
Treatment 3 (dose 10\%) & $0.002357 \pm 0.0017$ & 95 & $0.000643 \pm 0.0013$ \\
\hline
\end{tabular}

All the values are presented as means \pm SEM 
Table 2: Myeloperoxidase (MPO) concentrations of mouse ear biopsies

\begin{tabular}{lc}
\hline Groups & MPO concentration $\left(\mathrm{ng} \mathrm{mL}^{-1}\right)$ \\
\hline Negative control & $2.324 \pm 0.034$ \\
Vehicle & $56.659 \pm 0.512$ \\
Reference (hydrocortisone 1\%) & $3.198 \pm 0.080$ \\
Treatment 1 (dose 1\%) & $3.744 \pm 0.110$ \\
Treatment 2 (dose 5\%) & $3.445 \pm 0.060$ \\
Treatment 3 (dose 10\%) & $2.720 \pm 0.025$ \\
\hline
\end{tabular}

All the values are presented as means \pm SEM

Hydrocotisone cream a product belonging to the Glucocorticoid (GC) family is the most common anti-inflammatory agent used to treat skin inflammations (Ahluwalia, 1998). Interaction of GCs with the glucocorticoid receptors cause to form glucocorticoid-glucocorticoid receptor complex. The above mentioned complex translocate into nucleus and adapt inflammatory responses via suppressing or activating some relative genes, inhibiting the activities of Activator Protein-1 (AP-1) (a pro-inflammatory transcriptional factor) and or increasing the dilapidation of the specific mRNAs (Saklatvala, 2002). Besides, Kazumi et al. (1995) have shown that topical GCs inhibit croton oil-induced ear edema by inhibiting prostaglandin $\mathrm{E}_{2}\left(\mathrm{PGE}_{2}\right)$.

Although, findings of the current study do not express mechanism(s) of action of haruan based cream in inhibiting of mouse ear edema but a review and evaluation of the main components of Haruan aqueous extract as the main part of Haruan based cream and the previous related studies may suppose some probable mechanisms. As was mentioned before, the croton oil induces edema with mediating eicosanoids $\left(\mathrm{PGE}_{2}\right.$ and $\mathrm{LTB}_{4}$ ) bradykinin and some cytokines such as TNF- $\alpha$. There is one study has reported that intraperitoneal haruan water extract inhibited rat paw edema induced by prostaglandins whereas it did not affect edema induced by mast cell secretions (histamine and bradykinin) (Mohd. Hassan, 2005). Besides, there are several reports that anti-inflammatory property of Haruan extracts may be due to their high fatty acids and amino acids content (Mat Jais et al., 1994; Zakaria et al., 2006). The fatty acid composition of haruan aqueous extract are Saturated Fatty Acids (SFA) including palmitic, stearic, myristic and hepatadecanoic acids, Mono-Unsaturated Fatty Acids (MUFA) including oleic, elaidic, myristoleic and palmitoleic acids and finally Poly-Unsaturated Fatty Acids (PUFA) including linoleic and arachidonic acids (Dahlan-Daud et al., 2010).

As regards Arachidonic Acid (AA) is a precursor of PGs and $\mathrm{LTB}_{4}$ (two important inflammatory mediators), there is an important question must be answered why different haruan extracts with a high content of AA present an anti-inflammatory effect. Huang et al. (2001) reported that presence of $\mathrm{N}$-arachidonylglycine (a lipo-amino acids), blocks inflammatory process in rat brain and other tissues. Besides, previous studies shown that linolenic acid inhibit inflammation via suppressing the production of $\mathrm{LTB}_{4}$ and boosting the construction of 15-lipoxygenase products (Lu et al., 2007). Therefore, anti-inflammatory effects of Haruan extracts despite the presence of arachidonic acids can be explained with the simultaneous existence of the above-mentioned lipo-amino acids and linoleic acid in their composition. Furthermore, studies showed that presence of two other fatty acids, stearic and oleic acids which also find in Haruan aqueous extract, inhibit inflammation by decreasing the activity of Polymorphonuclear leukocytes (PMNs) (Michelle et al., 2004). Besides, integration of stearic and oleic acids into cell membrane phospholipids change membrane fluidity that in its turn cause to change some functions of cells such as activation of PMNs (Crocker et al., 2001). On the other hand, it has been found that oleic acid suppresses inflammation via attenuating the expression of endothelial leukocyte adhesion molecules (Massaro and Caterina, 2002). Therefore dose dependent effect of Haruan based cream in inhibition of MPO activity found in the current study can be related to the above mentioned two fatty acids stearic and oleic acids.

Based on the results of a study has done by Petroni et al. (1994) production of IL-1 $\beta$, IL- 6 and TNF- $\alpha$ can be inhibited in presence of Polyunsaturated Fatty Acids (PUFA). So, with regard to existence of two polyunsaturated fatty acids linoleic and arachidonoic acids in Haruan aqueous extract, researchers can conclude that a part of acute anti-inflammatory properties of Haruan based cream is related to the mentioned two polyunsaturated fatty acids.

\section{CONCLUSION}

Evidences obtained from the present study on the one side support the previous results that had shown the anti-inflammatory effects of haruan extracts in other animal models such as carrageenan or cotton pellet granuloma and on the other side, introduce a new topical biomedical product with a potency as great as hydrocortisone in inhibition of inflammation. It is suggested that topical anti-inflammatory effects of Haruan based cream is contributed to its bioactive substances content. The presence of molecules such as linoleic acid, stearic acid, oleic acid and compound(s) like $\mathrm{N}$-arachidonylplycine that their anti-inflammatory activities have been proven previously can be 
responsible for anti-inflammatory effects of Haruan based cream. However, further studies are required to determine accurate mechanism of action of haruan based cream in inhibition of acute inflammation and also to identify bioactive component(s) of this new natural based product.

\section{ACKNOWLEDGEMENT}

The researchers are grateful to Faculty of Medicine and Health Sciences, University Putra Malaysia.

\section{REFERENCES}

Ahluwalia, A., 1998. Topical glucocorticoids and the skinmechanisms of action: An update. Mediators Inflamm., 7: 183-193.

Baie, S. and K.A. Sheikh, 2000. The wound healing properties of Channa striatus-cetrimide cream-wound contraction and glycosaminoglycan measurement. J. Ethnopharmacol., 73: 15-30.

Bralley, E.E., P. Greenspan, J.L. Hargrove, L. Wicker and D.K. Hartle, 2008. Topical anti-inflammatory activity of Polygonum cuspidatum extract in the TPA model of mouse ear inflammation. J. Inflamm., Vol. 5 10.1186/1476-9255-5-1

Cabrini, D.A., H.H. Moresco, P. Imazu, C.D. da Silva and E.F. Pietrovski et al., 2010. Analysis of the potential topical anti-inflammatory activity of averrhoa Carambola L. in mice. Evid. Based Complement Alternat. Med.

Crocker, I.P., N. Lawson, P.N. Baker and J. Fletcher, 2001. The Anti-inflammatory effects of circulating fatty acids in obstructive jaundice: Similarities with Pregnancy-induced immunosuppression. Q. J. Med., 94: 475-484.

Dahlan-Daud, C.K., A.M. Mat Jais, Z. Ahmad, A. Akim and A. Adam, 2010. Amino and fatty acid compositions in Haruan traditional extract (Hte). Boletin Latinoamericano Caribe Plantas Med. Aromat., 9: 414-429.

Faith, M., A. Sukumaran, A.B. Pulimood and M. Jacob, 2008. How reliable an indicator of inflammation is myeloperoxidase activity? Clinica. Chimica. Acta., 396: 23-25.

Fariba, S., P. Khazaeli and N. Alli, 2009. In vivo evaluation of anti-inflammatory activity of topical preparations from fenugreek (Trigonella FoenumGraecum L.) seeds in a cream base. Iranian J. Pharm. Sci., 5: 157-162.
Huang, S.M., T. Bisogno, T.J. Petros, S.Y. Chang and P.A. Zavitsanos et al., 2001. Identification of a new class of molecules, the arachidonyl amino acids and characterization of one member that inhibits pain. J. Biol. Chem., 276: 42639-42644.

Kazumi, I., E. Mishima, M. Miura, N. Sakai and S. Shimao, 1995. Effect of Ru 486 on the atrophogenic and antiinflammatory effects of glucocorticoids in skin. J. Dermatol. Sci., 10: 151-158.

Krishnaraju, V. Alluri, C.B.M. Rao, D. Sundararaju, K. Sengupta and G. Trimurtulu, 2009. Anti-inflammatory activity of vitex Leucoxylon $\mathrm{L}$. bark extracts against freund's complete adjuvant induced arthritis in sprague dawley rat. Am. J. Infect. Dis., 5: 68-73.

Lu, T.C., Y.Z. Ko, H.W. Huang, Y.C. Hung, Y.C. Lin and W.H. Peng, 2007. Analgesic and anti-inflammatory activities of aqueous extract from Glycine tomentella root in mice. J. Ethnopharmacol., 113: 142-148.

Massaro, M. and R.D. Caterina, 2002. Vasculoprotective effects of oleic acid: Epidemiological background and direct vascular antiatherogenic properties. Nutr. Metab. Cardiovasc. Dis., 12: 42-51.

Mat Jais, A.M., 2007. Pharmacognosy and pharmacology of Haruan (Channa striatus), a medical fish with wound healing properties. Boletin Boletin Latinoamericano y del Caribe de Plantas Medicinales y Aromaticas, 6: 52-60.

Mat Jais, A.M., R. McCullock and K. Croft, 1994. Fatty acid and amino acid composition in Haruan as a potential role in wound healing. Gen. Pharmacol., 25: $947-950$.

Mat Jais, A.M., Y.M. Dambisya and T.L. Lee, 1997. Antinociceptive activity of channa striatus (Haruan) extracts in mice. J. Ethnopharmacol., 57: 125-130.

Mat Jais, A.M., R. Fung, E. Bosi, C. Platell, R. McCauley and K. Croft, 1998. Preliminary evidence on the potential of Haruan (Channa striatus) for wound healing. Mal. Applied Biol., 27: 50-51.

Matsuo, T., K. Kuriyama, Y. Miyazaki, S. Yoshida and M. Tomonaga et al., 2003. The percentage of myeloperoxidase-positive blast cells is a strong independent prognostic factor in acute myeloid leukemia, even in the patients with normal karyotype. Leukemia, 17: 1538-1543.

Michelle, N.Y.T., G. Shanthi and M.Y. Loqman, 2004. Effect of orally administered Channa striatus extract against experimentally-induced osteoarthritis in rabbits. Int. J. Appl. Res. Vet. Med., 2: 171-175.

Mohd. Hassan, S., 2005. Anti-Inflammatory and Antinociceptive Properties of Three Local Channa Species Crude Extracts. Universiti Putra Malaysia, Malaysia. 
Nakadate, T., 1989. The mechanism or skin tumor promotion caused by phorbol esters: Possible involvement of arachidonic acid cascade/ Lipoxygenase, protein kinase $\mathrm{C}$ and calcium/calmodulin systems. Jpn. J. Pharmacol., 49: $1-9$.

Okoli, C.O., P.A. Akah, S.V. Nwafor, A.I. Anisiobi, I.N. Ibegbunam and O. Erojikwe, 2007. Antiinflammatory activity of hexane leaf extract of Aspilia africana C.D. Adams. J. Ethnopharmacol., 109: 219-225.

Petroni, A., M. Salami, M. Blasevich, N. Papini and C. Galli, 1994. Inhibition by N-3 fatty acids of arachidonic acid metabolism in a primary culture of astroglial cells. Eurochemical. Res., 19: 1187-1193.

Saklatvala, J., 2002. Glucocorticoids: Do we know how they work? Arthritis Res., 4: 146-150.

Sherwood, E.R. and T. Toliver-Kinsky, 2004. Mechanisms of the inflammatory response. Best Pract. Res Clin. Anaesthesiol., 18: 385-405.
Soliman, K.F.A., M.R.I. Soliman, J.O. Owasoyo and C.A. Walker, 1983. Diurnal variation in the phlogogenic response of rats to inflammatory agents. J. Pharm. Pharmacol., 35: 388-389.

Somchit, M.N., M.H. Solihah, D.A. Israf, Z. Ahmad, A.K. Arifah and A.M. Mat Jais, 2004. Antiinflammatory activity of channa striatus, channa micropeltes and channa lucius extracts: Chronic inflammatory modulation. J. Orient. Pharm. Exp. Med., 4: 91-94.

William, J.G. and L.C.L. Stanfield, 2002. Principles of Human Physiology. 1st Edn., Vol 1, Daryl Fox, San Francisco, CA, USA.

Zakaria, Z.A., A.M. Mat Jais, M.N. Somchit, M.R. Sulaiman and C.A. Fatimah, 2006. Report on som of the physical properties of bioactive compounds responsible for the channa striatus fillet extract antinociceptive activity. J. Biol. Sci., 6: $680-686$. 